\title{
Give me five!
}

_ Die Zahl Fünf erkläre ich hiermit zur neuen Glückszahl. Zumindest für diesen Monat. Denn im Oktober läuft sie uns immer wieder über den Weg. Zum Beispiel bei unserem ergotag, der dieses Jahr zum fünften Mal stattfand. Mit dem Thema „Umschriebene Entwicklungsstörungen motorischer Funktionen (UEMF)“ war das Symposium am Puls der Zeit. Einige Referenten haben an der erst kürzlich erschienenen Leitlinie zu dieser Diagnose mitgearbeitet und konnten aus erster Hand davon berichten. Wer nicht teilnehmen konnte, erfährt auf Seite 21, wo man die neue Leitlinie findet. Bis sich die sperrige Bezeichnung des Störungsbildes - die Abkürzung UEMF klingt meiner Ansicht nach auch nicht schöner - in Deutschland durchsetzt, wird es wohl noch ein wenig dauern. Denn viele Therapeuten haben sich bereits mit dem englischen Ausdruck „Developmental Coordination Disorder (DCD)“ angefreundet bzw. sprechen von „motorischen Entwicklungsstörungen“.

_ Mit unserem kleinen Tollpatsch Mario möchten wir Sie einladen, fünf verschiedene „Therapiebrillen“ aufzusetzen. Schauen Sie seiner Therapeutin ab Seite 16 bei der Behandlung des fiktiven Paradebeispiels für Kinder mit UEMF über die Schulter. Blicken Sie dabei gleichzeitig hinter die Kulissen der Sensorischen Integrationstherapie, der Verhaltenstherapie, des Aufmerksamkeitstrainings und des Neurofeedbacks, des Grafomotoriktrainings und des CO-OP. Diese komplett unterschiedlichen Ansätze zeigen erneut sehr eindrücklich, wie vielfältig unser Beruf doch ist.

_ Natürlich kommen nicht nur die Pädiatriebegeisterten bei uns auf ihre Kosten. Wer sein Wissen über Röntgen, Sonografie $\mathcal{E}$ Co. auffrischen möchte oder die Unterschiede bildgebender Verfahren für die nächste Klausur lernen muss, ist bei uns ebenfalls an der richtigen Stelle. Auf Seite 28 finden Sie die fünf wichtigsten Verfahren im Überblick.

_ Zu guter Letzt können Sie in dieser Ausgabe fünf Gewinne absahnen. Ich drücke Ihnen die Daumen - davon habe ich allerdings nur zwei!

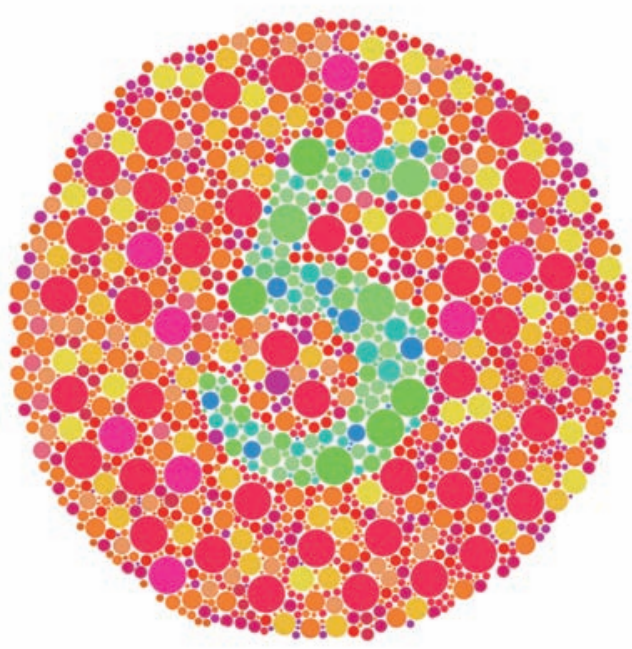

Wenn Sie hier eine Fünf sehen, dann haben Sie den Farb-Sehtest bestanden und leiden nicht an einer Rot-Grün-Schwäche.

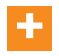

4.

\section{ZU GEWINNEN}

Kursplatz

1 Kurs nach Wahl

Seite 45

Bücher

3-mal das Duo „Körperhaltungen analysieren und verbessern" und „Entspannungstraining für Kiefer, Nacken, Schultern“

Seite 23

4-mal „Detektive in Weiß“ Seite 26

2-mal „Früher war hier das Ende der Welt “

Seite 32

Im ergopraxis.Refresher

2-mal „Patientenedukation“

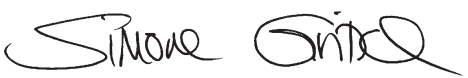

